\title{
National Fall Prevention Workshop: stepping up pan-Canadian coordination
}

\author{
Centre for Health Promotion, Public Health Agency of Canada; British Columbia Injury Research and Prevention \\ Unit (BCIRPU)
}

\section{Background}

About one in three Canadian seniors will experience a fall at least once each year. ${ }^{1-4}$ Such falls are the leading cause of injury-related hospitalizations among older people. ${ }^{5}$ Apart from causing injury, falls can result in chronic pain, reduced quality of life and, in severe cases, death. Psychological effects of a fall may cause a post-fall syndrome that includes dependence on others for daily activities, loss of autonomy, confusion, immobilization and depression. ${ }^{1}$

Falls and the resulting injuries often occur due to a combination of factors, including health conditions associated with aging such as vision problems, osteoporosis, dementia and symptoms of a chronic disease. They can be due to the side effects of medications, environmental hazards and risk-taking behaviours.

Fall prevention initiatives and strategies are taking place in all provinces and territories and at the national level. To enhance the collaborative understanding of these initiatives, a National Fall Prevention Workshop was held at the Canadian Injury Prevention and Safety Promotion Conference in Vancouver, British Columbia, on 17 November 2011. The Workshop was co-hosted by the British Columbia Injury Research and Prevention Unit (BCIRPU) and the Public Health Agency of Canada (PHAC). Fall prevention leads from each province and territory were invited to present their most recent activities and their plans. This event proved to be highly successful with over 60 attendees representing all the provinces and Yukon (see Table 1).

TABLE 1

Workshop attendees and presenters

\begin{tabular}{|ll}
\hline Jurisdiction & Agency represented \\
\hline Canada & Division of Aging and Seniors, Public Health Agency of Canada \\
\hline British Columbia & $\begin{array}{l}\text { BC Ministry of Health } \\
\text { BC Injury Research and Prevention Unit }\end{array}$ \\
\hline Alberta & $\begin{array}{l}\text { Health Professions Strategy \& Practice, Alberta Health Services } \\
\text { Alberta Centre for Injury Control \& Research } \\
\text { Fall Risk Management Program, Alberta Heath Services - Calgary Zone }\end{array}$ \\
\hline Saskatchewan & Acquired Brain Injury Partnership Project, Ministry of Health \\
\hline Manitoba & $\begin{array}{l}\text { Department of Manitoba Healthy Living, Youth and Seniors, Healthy } \\
\text { Living and Populations Branch }\end{array}$ \\
\hline Ontario & $\begin{array}{l}\text { Ontario Injury Prevention Resource Centre } \\
\text { SMARTRISK }\end{array}$ \\
\hline Quebec & Institut national de santé publique du Québec \\
\hline New Brunswick & $\begin{array}{l}\text { Office of the Chief Medical Officer of Health, New Brunswick } \\
\text { Department of Health }\end{array}$ \\
\hline Prince Edward Island & Spectrum Solutions \\
\hline Nova Scotia & Nova Scotia Department of Health and Wellness \\
\hline $\begin{array}{l}\text { Newfoundland and } \\
\text { Labrador }\end{array}$ & $\begin{array}{l}\text { Chronic Disease Control Division, Department of Health and } \\
\text { Community Services }\end{array}$ \\
\hline Yukon & Arctic Institute of Community-Based Research \\
\hline
\end{tabular}

\section{Workshop objectives}

The objectives of the 2011 National Fall Prevention Workshop were to

1) bring together federal, provincial and territorial leads interested in collaborating on evidence-based, clinically relevant programming, policy and practice to reduce the risk of falls and related injuries among older adults in Canada;

2) present model strategic fall prevention plan components from each province/ territory;

3) discuss current best practices and their application in each province and territory, including data standardization for fall-related morbidity, fall risk assessment tools and protocols, implementation of best practices and evaluation of progress and outcomes.

\section{Summary of workshop discussions}

\section{Education and training}

Education of health care providers was identified as a priority, with the Canadian Fall Prevention Curriculum (CFPC) cited by most participants as the training program of choice. Standardizing and integrating fall prevention training into postsecondary education was considered an important next step. 


\section{Accreditation}

Accreditation Canada's Required Organizational Practices for fall prevention was frequently cited as the impetus for developing fall prevention strategies in health care settings. ${ }^{6}$

\section{Leadership and strategic planning}

Many attendees identified that while work on fall prevention is ongoing in parts of their jurisdictions, there is no consistency across their province or territory. Some participants recommended developing a sustainable, evidence-based fall prevention strategy with feasible solutions to facilitate a coordinated approach; however, it was noted that fiscal considerations were a limiting factor to implementing such initiatives.

\section{Team communication}

Networks and coalitions were frequently referred to as an important medium for professionals to communicate about implementing fall prevention programming.

\section{Data and surveillance}

Jurisdictions that reported having access to data were able to demonstrate a positive relationship between their fall prevention programs and a reduction in falls and fall-related injuries. Several jurisdictions reported that lack of data and surveillance at the setting and at provincial/territorial level made it difficult to evaluate programs rigorously.

\section{Next steps}

The 2011 National Fall Prevention Workshop introduced the idea of a National Fall Prevention Collaborative composed of the provincial and territorial leads who presented at the workshop, with the potential for other interested stakeholders to participate. The presenters all agreed to build on the momentum from the workshop to formally establish a practice network and virtual library of best/promising practices. In the interests of further collaboration-and building on the success of the workshop-participants recommended a larger-scale national conference on fall preventions, which could take place in 2014 , to bring together provincial/territorial and federal health care providers and policy makers as well as other interested stakeholders to share knowledge and create networks that further advance fall prevention initiatives.

\section{Acknowledgements}

The workshop organizers wish to thank the workshop attendees for their involvement and collaboration. Special thanks are also extended to Joanne Veninga, Lori Wagar and Sarah Elliot for their assistance in organizing the workshop.

\section{References}

1. World Health Organization. WHO global report on falls prevention in older age. Geneva (CH): World Health Organization; 2007.

2. Scott VJ, Peck SH, Kendall PR. Prevention of falls and injuries among the elderly: a special report from the Office of the Provincial Health Officer, January 2004. Victoria (BC): Provincial Health Officer, British Columbia Ministry of Health Planning; 2004.

3. Tinetti ME, Speechley M. Prevention of falls among the elderly. N Engl J Med. 1989;320(16):1055-9.

4. O'Loughlin JL, Robitaille Y, Boivin JF, Suissa S. Incidence of and risk factors for falls and injurious falls among the community-dwelling elderly. Am J Epidemiol. 1993;137:342-54

5. Public Health Agency of Canada. Report on seniors' falls in Canada. Ottawa (ON): Division of Aging and Seniors, Public Health Agency of Canada; 2005.

6. ROPS: Required Organizational Practices September 2011. Ottawa (ON): Accreditation Canada; 2011 Jul [cited 2012 Feb 2]. Available from: http://www.accreditation.ca /uploadedFiles/ROP\%20Handbook.pdf 